\title{
Mood Disorders And Their Pharmacological Treatment During Pregnancy: Is the Future Child Affected?
}

\author{
CATHERINE MONK, ELIZABETH M. FITELSON, AND ELIZABETH WERNER
}

Department of Psychiatry, Columbia University, New York, New York 10032

\begin{abstract}
Nearly half the US population will meet criteria for a neuropsychiatric disorder at some point in their lives, and 1 in 17 has a seriously debilitating illness. Although not all affected adults had an identified disorder as a child, increasingly these psychopathologies are conceptualized as the late-stage culmination of aberrant developmental processes shaped by a complex interplay of genes and experience, including experiences in utero. Decades of studies with pregnant animals demonstrate that stress-elicited perturbations in maternal biology affect offspring neurodevelopment. Studies of stress in pregnant women largely mirror these findings. Pregnant women with anxiety and/or depression experience greater life stress, and illness-related alterations in their neurobiology, with a potential to impact fetal neurobehavioral development via associated changes in the intrauterine environment and/or pharmacologic interventions. This article critically reviews findings on child development (including fetal neurobehavior) related to maternal depression, anxiety, and pharmacological treatments, primarily selective serotonin reuptake inhibitors (SSRIs). The hypothesis under review is that, in addition to genetics and characteristics of the postnatal environment, the familial transmission of risk for neuropsychiatric disorders involves a "third path"-prenatal exposure to psychiatric illness and its treatment. (Pediatr Res 69: 3R-10R, 2011)
\end{abstract}

$\mathrm{D}$ epression and/or anxiety will affect nearly half the US population at some point in their lifetimes (1); women are twice as likely as men to suffer from these disorders (2), and the childbearing years are coincident with the greatest risk period (1). Recent studies indicate that $10 \%$ of pregnant women meet criteria for major depression, and as many as 18\% have some depressive symptoms $(3,4)$. Anxiety symptoms affect $\sim 13 \%$ of pregnant women (4). Recent reports show that psychopharmacological treatment during pregnancy has dramatically increased, largely driven by the use of selective serotonin reuptake inhibitors (SSRIs) $(5,6)$, with one study indicating that fully $10 \%$ of pregnancies in some populations involve exposure to antidepressant medication (7). The current focus to "re think mental illness" as disorders of brain circuits that are the late-stage culmination of aberrant developmental processes shaped by a complex interplay of genes and experience, including prenatal experience (8), has

Received November 18, 2010; accepted January 13, 2011

Correspondence: Catherine Monk, Ph.D., The Women's Program, Departments of Psychiatry, Columbia University, 1150 St Nicholas Avenue, Suite 1-121, New York, NY 10032; e-mail: cem31@ columbia.edu

C.M. is supported by Grant MH001928-01A1 from the National Institutes of Health particular relevance for the susceptibility to future psychopathology that in utero exposure to these maternal disorders, and their treatments, may confer.

Studies have consistently shown that maternal psychiatric disorders in the postpartum period, and later in development, have a negative impact on child neuropsychiatric outcomes $(9,10)$. Accumulating evidences suggest that maternal psychiatric symptoms during pregnancy also contribute to placing the future child at risk for neuropsychiatric disorders. In addition, the medications used to treat depression and anxiety also may affect neurobehavioral development. In what follows, we review the most recent evidence suggesting that prenatal exposure to psychiatric illness and its treatment may be a "third path" by which familial transmission of risk for neuropsychiatric disorders occurs. Specifically, the following research findings are discussed: maternal prenatal depression and anxiety and children's increased risk for psychopathology; maternal prenatal mood symptoms and at-risk infant temperament and perinatal profile, maternal prenatal mood symptoms and variation in fetal neurobehavior; use of the common psychotropic medications for depression and anxiety, SSRIs, during pregnancy and neonatal adaptation syndrome (NAS), neonatal neurobehavioral toxicity, and neurodevelopmental outcomes in humans and animal models. Although these studies are largely correlational, possible pathways for the effects are discussed, including 1) the maternal hypothalamic pituitary adrenal (HAP) axis, 2), placental functioning, and 3) uterine blood flow, with down stream effects potentially influencing synaptogenesis, neurotransmitter function, and receptor expression in the developing brain (11). To provide perspective for this emerging data, studies are critiqued with respect to methodological approaches, in particular, the challenging issue of accounting for postnatal environmental influences and whether an underlying psychiatric disease was controlled for when identifying medication effects.

\section{Depression and Anxiety Symptoms During Pregnancy and Child Neuropsychiatric Outcomes}

Pregnant women's experience of a range of traumatic, as well as chronic and common life stressors, is associated with significant deviations in children's neurodevelopment, includ-

Abbreviations: CRH, corticotrophin-releasing hormone; HR, heart rate; SSRI, selective serotonin reuptake inhibitor; UBF, uterine blood flow 
ing increased risk for mixed handedness, autism, affective disorders, and reduced cognitive ability $(12,13)$. Similarly, antenatal anxiety and/or depression have been shown to predict increased risk for future mental illness in the offspring (14). A recent longitudinal study of inner city pregnant women that followed $84 \%$ of the children to age $16 \mathrm{y}$, and based results on at-home structured interviews, found that adolescents exposed to antenatal depression had a 4.7-fold greater odds of being depressed than those not exposed (15). Similarly, striking results have emerged from the Avon Longitudinal Study of Parents and Children (ALSPAC), a prospective, longitudinal study of more than 7000 pregnant women and their offspring based on parent reports. This data set has produced results showing that: 1) prospectively collected selfrated higher anxiety levels during pregnancy increased the risk for overall number of identified emotional and behavioral problems in both boys and girls aged $4 \mathrm{y}$ and greater levels of inattention and hyperactivity in boys when controlling for the effect of maternal postpartum $\operatorname{mood}(14), 2)$ the effects are specific to prenatal anxiety versus prenatal or postpartum depression (16), 3) the association between prenatal anxiety and these behavioral problems is maintained upto $6.5 \mathrm{y}$ of age (17), and 4) in a subsample at the age of $10 \mathrm{y}$, higher antenatal anxiety predicts higher initial cortisol upon awakening and at $4 \mathrm{pm}$, suggesting alteration in hypothalamic-pituitary-adrenal (HPA) axis functioning (18). Van den Bergh et al. (19), also found that in a community sample of pregnant women, antenatal anxiety predicted 1) attention deficit hyperactivity disorder (ADHD) symptoms in 8- to 9-y-olds as judged by maternal and teach reports, 2) impulsivity on a laboratory protocol at the age of 15 y $(20), 3)$ greater errors for boys on a continuous performance task (the gold standard for identification of ADHD) (21), and 4) a high, flattened cortisol profile, which in girls was associated with depressive symptoms (22).

The consistent findings of antenatal anxiety predicting ADHD symptoms and alteration in HPA axis functioning from a large cohort study using self-report measures and small community samples based on behavioral observations are particularly compelling. Results by Pawlby et al. predicting heightened risk for depression associated with antenatal depression exposure show a significant effect for the in utero exposure but have yet to be replicated. In a recent follow-up study of school age children first enrolled when their mothers were pregnant, Buss et al. (23) found that exposure to pregnancy anxiety predicted a reduction in gray-matter density in the prefrontal cortex, a region involved in stress hormone regulation (24), and thus consistent with the HPA axis findings (23). However, substantiation with neurobiological data of these maternal mood-based prenatal effects-albeit correlational-does not rule out one of the primary concerns with these findings: inadequate control for diverse factors in the postnatal environment for which women's antenatal psychiatric symptoms may be a marker, and, in response to which offspring neurobehavioral development may be altered. Although postpartum mood is routinely controlled for in these studies, when findings extend years beyond the prenatal exposure, it is logistically difficult, and statistically unwieldy, to simultaneously test for the influence of other salient environmental factors that affect brain-behavior development and covary with maternal psychiatric symptoms, for example chaotic home environments (25).

\section{Psychiatric Symptoms During Pregnancy and An At-Risk Perinatal Profile}

Before any significant exposure to postnatal environmental influences, associations between pregnant women's symptoms of depression and anxiety, and offspring functioning, can be identified. Research over several decades indicate that newborns of depressed mothers have lower motor tone and endurance, are less active, less robust, more irritable, and less easily soothed $(26,27)$. A prospective study showed that pregnant women's self-reported levels of anxiety was associated with lower scores on subscales related to attention skills on the Neonatal behavioral assessment as early as 3 wk (28). Prenatal factors such as women's psychosocial functioning have been shown to contribute to the development of a temperamentthe relatively stable profile of infant reactivity and regulation. Specifically, in a prospective study, prenatal anxiety and depression predicted greater infant cry and motor behavior in response to a standardize series of novel stimuli (the Harvard Infant Behavioral Reactivity Protocol) at 4 mo (29). In a report from our laboratory (30) also based on the Harvard protocol, although using a standard clinician interview [the Structured Clinical Interview for the DSM-IV (SCID)] to characterize third-trimester pregnant women's psychiatric symptomatology, a prenatal diagnosis of an anxiety or depressive disorder was a significant predictor of infant cry, but not motor, reactivity. Infants who were categorized as low reactive (low motor and low cry reactivity) were 8.4 times more likely than the other reactivity groups to not have a mother diagnosed with a mood disorder (30). Other recent studies have found relationships between prenatal depression and negative affect at 6 mo of age (31) and posttraumatic stress disorder in pregnant women's response to the terrorist attacks of September 11, 2001, and greater distress to novelty in 9-mo old infants (32).

Other studies have identified variation in infant neurobiology associated with in utero exposure to maternal anxiety. In one study, 4- and 14-mo-old infants born to women with diagnosed panic disorder were found to have higher daily cortisol and disturbed sleep (33). Two similar reports showed that prenatal anxiety or anxiety and depression are associated with elevations in infant cortisol at 4 (34) and 7 mo of age (35). Higher resting cortisol also has been identified in newborns of depressed pregnant women (36). Hyperactivity in the HPA axis has particular relevance for neuropsychiatric disorders given the role of stress experiences in the pathophysiology of many forms of psychopathology (37).

To more fully investigate the influence of the prenatal environment on child neurobehavioral development, specifically women's anxiety and depression, we, as well as others, have reasoned that if the psychosocial functioning of pregnant women affects long-term development of offsprings, we should be able to identify evidence of that influence when it 


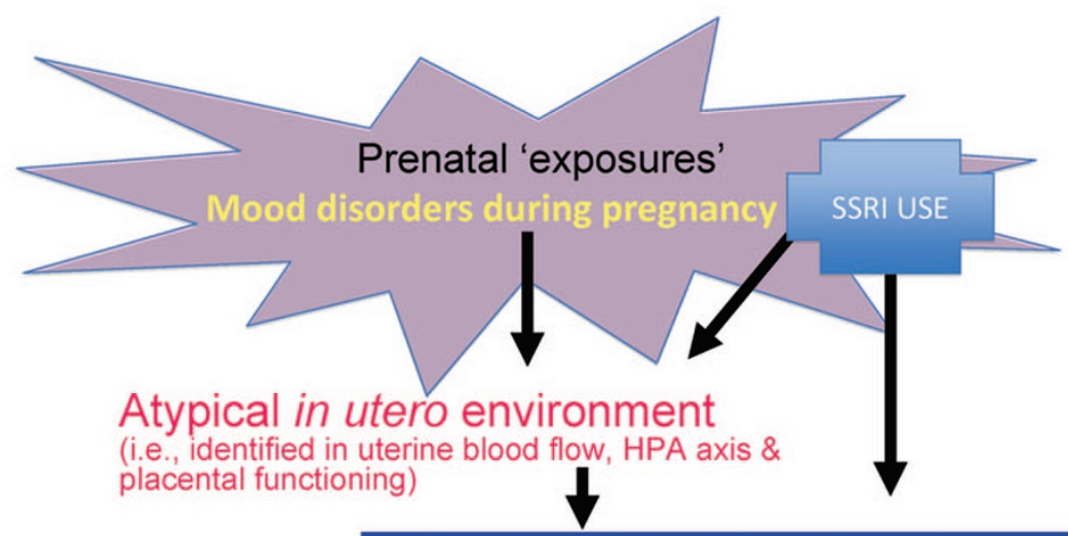

Figure 1. Fetal origins of neuropsychiatric disorders. Conceptual model of the potential relevance of mood disorders during pregnancy for children's neurodevelopmental outcomes.

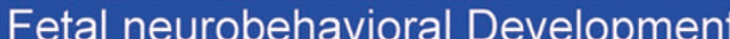

(i.e., ANS \& HPA axis development, synaptogenesis neurotransmitter function, glucocorticoid receptor expression in the developing brain)

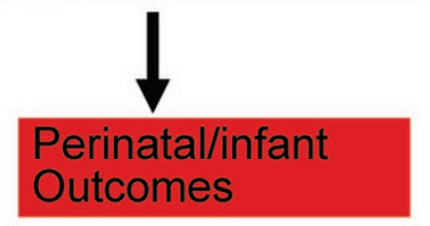

occurs, that is, during the prenatal period. In previous reports, we showed that prenatal maternal depression, comorbid depression and anxiety, and high-trait anxiety, predict an increase in fetal heart rate (HR) during women's laboratorybased acute stress experience (Stroop test) compared with fetuses of euthymic women who show no significant HR change $(38,39)$. Because women across diagnostic groups had comparable cardiorespiratory responses to the stressor, we interpreted these findings as suggesting greater reactivity to stimuli in fetuses of women positive for psychiatric symptoms. Others have found that maternal depression during pregnancy is associated with greater fetal movement and slower return to baseline HR after vibroaccoustic stimulation applied to the women's abdomen (40). Increases in fetal HR often are coincident with fetal movements (41); these findings are thus consistent in suggesting that greater fetal reactivity to external stimuli may be a characteristic of fetal neurodevelopment when pregnant women experience significant mood dysregulation. However, findings by Dieter et al. (42) showed an association between depressed and anxious mothers and faster rates of fetal HR habituation to an external stimulus. In a particularly elegant study, fetal behavior related to induced maternal emotion predicted infant temperament (43). Specifically, pregnant women viewed an evocative film of labor and delivery, whereas their third-trimester fetuses were monitored for movement and HR activity. Fetuses that showed more significant decreases in HR variability and movement during the film (characterized as "reacting more intensely") were judged by a laboratory protocol to be more irritable at $6 \mathrm{wk}$ old (43). To demonstrate a fetal response to maternal emotion, and to show functional significance with respect to future temperament of this fetal reactivity with a minimal window for postnatal influence, substantially supports the conceptual model of fetal origins of neuropsychiatric disorders, and the possibility that over the course of gestation, maternal anxiety or depression could impact fetal development (Fig. 1).

Converging data from epidemiological, community, and clinical studies investigating the impact of prenatal depression and anxiety on offspring neurobehavioral development show supportive evidence across behavioral and biological domains in findings with adolescents, children, and fetuses. That effects can be detected before the influence of the postnatal environment (perinatal results), and that some consistency is evident in specific results (negative reactivity in temperament, elevations in resting cortisol, and ADHD symptoms) provides validation of the prenatal transmission hypothesis. However, weaknesses in the studies should be noted: there is a lack of specificity with respect to developmental effects of prenatal depression versus anxiety. This is consistent with the high comorbidity of these disorders and also may be because both of these forms of affect dysregulation are highly associated with stress (4), which raises the question: is the true "signal" in these studies maternal stress, a model strongly supported by animal and human studies? Moreover, what level of prenatal affect regulation has a negative impact on perinatal neurobehavioral development? Some of the results are based on self-reports of mood, whereas others on diagnosed depression and anxiety disorders. Is assessment of maternal postpartum depression and anxiety sufficient to capture the postnatal influences that could be related to the identified outcome? Are these maternal prenatal characteristics associated with child outcome because they are markers for, or highly correlated with, postnatal factors that are the true causative variable? Several studies that have controlled for postpartum maternal psychological state have been able to demonstrate that prenatal anxiety and depression impact infant neurobehavior independent of postpartum mood $(16,28,29)$. Moreover, are these results primarily the identification of shared familial genetic 
traits that manifest in risk factor profiles before the frank disorder appears? Animal models of prenatal stress argue against this interpretation (44). A recent study with pregnant women aimed to tease apart gene versus prenatal environment influences by including donor egg recipients (45) determined that the prenatal stress-ADHD association reflects shared genes. Although this is an ingenious research design, the variability in social context and parenting between donor and nondonor egg childbearing (i.e. parenting involvement), and the impact this may have on postnatal environments and subsequent child development (46), was not well considered, leaving the results open to interpretation. Finally, although the stages of fetal brain development are well characterized, there is a lack of consistency across these studies, and of specificity, with respect to when during gestation "exposure" to maternal mood symptoms has an impact, and what are the outcomes $(16,18,22)$.

\section{Use of Psychotropic Medications During Pregnancy}

Perhaps in response to the improved recognition of psychopathology and its consequences on maternal and family health, SSRI, and other antidepressant exposure has become increasingly common in pregnant women. A retrospective cohort study of 105,335 pregnant women in a Medicaid database found that $8.7 \%$ of women giving birth had exposure to an antidepressant at some point in pregnancy, with the frequency of exposure increasing from 5.7\% of pregnancies in 1999 to $13.4 \%$ of pregnancies in 2003. Most of the increase was in SSRI exposure (7). In another US population-based study, the frequency of antidepressant use around childbearing increased from 2.5 to $8.1 \%$ between 1998 and 2005 (6). A populationbased prescription database study from the Netherlands estimated that the rate of SSRI use during pregnancy was 28.5 per 1000 live births for 2003-2004, an increase from 12.2 per 1000 in 1995 (5).

Studies attempting to determine the effects of antidepressant exposure on child outcomes related to neuropsychiatric risk must grapple with a number of intrinsically confounding factors, including the effects of underlying mental illness itself on neurodevelopment as discussed above, as well as associated demographic and behavioral factors that have known risks for child development. Even in attempting to control for these aspects through statistical analysis, matching, or propensity scoring, there still may be unmeasured or measured factors that are different between women who choose to take medication during pregnancy and women who do not require it for mental stability, or who choose not to take medication despite psychiatric symptoms. SSRIs are prescribed for a number of psychiatric and nonpsychiatric diagnoses, including depression, anxiety disorders, and pain disorders, making the exposed population heterogeneous and thus more difficult to standardize for study.

\section{Neonatal Adaptation Syndrome}

A neonatal syndrome consisting of CNS, motor, respiratory, and gastrointestinal signs has been found in babies exposed to SSRI medication in late gestation (47). Symptoms most com- monly consist of crying, jitteriness, tremor, feeding, reflux, sneezing, and sleep dysregulation, (48), whereas in rare cases may be associated with seizure. Premature infants may be more susceptible to this syndrome and may take longer to recover (49). The syndrome may be identified in up to $30 \%$ of babies exposed to SSRIs in late pregnancy (50), but the symptoms are usually mild and resolve with supportive care within 48 h to 2 wk of age (47).

\section{Antidepressant Exposure and Neonatal Toxicity}

Although SSRI-related poor adaptation has been postulated to be a drug withdrawal or toxicity syndrome, it is not clear whether stopping antidepressant medication before delivery has an impact in reducing rates of neonatal distress. To determine whether adverse perinatal outcomes are reduced if SSRI use is stopped before the last $2 \mathrm{wk}$ of pregnancy, Warburton et al. (51) examined linked administrative databases to determine timing of prescriptions filled for SSRIs at least $50 \mathrm{~d}$ after conception and continued either through labor or stopped at least $14 \mathrm{~d}$ before delivery. After controlling for length of gestational exposure and maternal depression severity via propensity score matching, there were no significant differences in the measured outcomes of length of hospital stay, respiratory problems, convulsions, or feeding difficulties. This finding suggests that stopping the medication before delivery to avoid adverse neonatal outcomes may be ineffective. The study also suggests that at least certain aspects of the previously described neonatal syndrome after SSRI exposure may represent not medication toxicity or withdrawal effect, but a neurobiological disturbance, which may in turn have potentially been caused by factors related to underlying maternal illness and/or fetal medication exposure. Neurobehavioral aspects of NAS were also characterized in a small, prospective study that looked at healthy, normal weight newborns in the first $2 \mathrm{~d}$ after delivery who were exposed or not exposed to SSRI medication in the third trimester (52). SSRIexposed newborns showed increased tremulousness, dysregulated behavioral state, greater amounts of uninterrupted rapid eye movement (REM) sleep, greater numbers of startles or sudden arousals, more generalized motor activity, and greater autonomic dysregulation. Mothers were matched for age, SES, and tobacco use, but there was no data on rates of depression and/or anxiety, and SSRI-exposed babies were born at lower GA. Despite this limitation, this study suggests that SSRI exposure is associated with immediate neurobehavioral changes in otherwise healthy neonates. Indeed, Oberlander et al. (53) found altered pain reactivity in newborns exposed to SSRI medication antenatally compared with nonexposed infants, which was sustained at follow-up investigation 2 mo postdelivery. A study looking at salivary cortisol levels in 3-mo old infants who were exposed to SSRIs in utero found evidence to support the hypothesis that prenatal SSRI exposure may alter HPA stress response patterns, as evidenced in reduced evening basal cortisol levels and differential cortisol responses to stress challenge (54). However, these effects were also mediated by maternal mood and breastfeeding status, suggesting a complex interplay between prenatal maternal 
mood, medication exposure, and postnatal exposure to medication and/or nutritional or caregiving factors.

\section{Antidepressant Exposure and Neurodevelopmental Outcomes}

A prospective study by Nulman et al. (55) compared children of mothers diagnosed with major depressive disorder (MDD) who were treated with tricyclic antidepressants (TCA) or fluoxetine through pregnancy compared with unexposed children. They found no differences in cognitive language or temperament effects between exposed and nonexposed babies. In contrast, they did find that children of mothers with longer duration of depression or more depressive episodes scored lower on measures of cognitive and language development. Casper et al. (56) compared children of mothers taking SSRIs in pregnancy with women with a diagnosis of MDD who were treated with supportive psychotherapy alone. Depression scores were similar between groups. There were no significant differences in mental development, but they did find lower scores in psychomotor development, and lower behavioral motor quality, with differences notable for tremulousness and find motor movements. A more recent study seems to support the finding of mild alterations in motor development in SSRIexposed children. This Danish birth cohort study compared infant developmental milestones at 6 and 19 mo of age in women who had taken antidepressants during pregnancy, women who reported a diagnosis of depression during pregnancy, and unexposed, nondepressed women (57). Children with in utero exposure to antidepressants in late pregnancy had delayed achievement of some gross motor milestones compared with the children of women with depression who did not take antidepressants. Second- and third-trimester exposed children sat without support a mean of $15.9 \mathrm{~d}$ later than nonexposed (95\% CI: 6.8-25.0) and walked $28.9 \mathrm{~d}$ later (95\% CI: $15.0-42.7)$. The effect was more pronounced in boys rather than girls. However, these motor delays were within the normal range for developmental milestones, and there were no significant differences in gross motor development at 19 mo. No other cognitive or social development measure was statistically different, with the exception of one measure of attention at 19 mo.

A longitudinal study looking at child developmental factors in mother-infant pairs who were or were not exposed prenatally to antidepressants found no evidence of increased internalizing (58) or externalizing (59) behaviors in exposed children at $4 \mathrm{y}$ old. Rather, measures of maternal depression and anxiety were significant predictors of internalizing behaviors in the exposed children. Of note, the women in the exposure group in these studies remained psychiatrically symptomatic through pregnancy and through much of the study period. A more recent study by Oberlander et al. (60) similarly found that maternal mood at 3-y follow-up was significantly associated with externalizing behaviors in a cohort of children exposed to serotonin medications antenatally. However, they also found that both current maternal anxiety and antenatal SSRI exposure was associated with internalizing behaviors in the children. The authors further explored the relationships between prenatal and maternal mood and anxiety and SSRI exposure effects as potentially mediated through the serotonin transporter SLC6A4 genotype. Specifically, they found that antenatal anxiety was significantly predictive of internalizing or externalizing behaviors only when allelic variation in this gene was accounted for in the model. Although limitations of the study include the use of maternal report in measuring child behaviors, the study offers a new path in examining the interactions of genes, prenatal and postnatal environment, and medication exposure in child development. To summarize, data on neurodevelopmental outcomes for children exposed prenatally to antidepressant medication is sparse, and limited by the lack of longer term outcome data, and the potential confound of simultaneous exposure to maternal mood disorders.

\section{Animal Models of SSRI Exposure and Its Neurodevelopmental Effects}

Animal studies suggest that exposure to SSRIs during early development (comparable with human in utero experience) result in lasting neurobehavioral effects in adolescent and adult offspring, including locomotor changes, a reduction in sexual activity in males, inhibition of exploratory behavior, and effects on REM sleep $(61,62)$. Research suggests that mice that experienced early postnatal fluoxetine exposure did not begin to display abnormal behavior until after puberty (61).

Animal models of the influence of prenatal SSRI exposure on offspring functioning are identifying an impact on outcomes that is, for the most part, less clearly recognized in humans via the available assessments. Whether a SSRI exposure influence is present in humans is not yet known. However, that these analog studies do not incorporate into the model the altered neurobiology associated with depression may limit the simple application of the results to humans.

\section{Pathways of Transmission}

There are primarily three hypothesized pathways by which women's antenatal depression and anxiety, and SSRI use, may be "transmitted" to the fetus, impacting neurobehavioral development. They are as follows: a) neuroendocrine processes (63) b) placenta functioning (64), and c) alterations in vascular activity that affect fetal oxygenation and nutrient delivery $(65,66)$.

Neuroendocrine. During human pregnancy, the placenta produces corticotropin releasing-hormone (CRH). However, unlike in the hypothalamus, glucocorticoids up-regulate placental CRH production, resulting in a positive feedback loop as $\mathrm{CRH}$ of placental origin contributes to elevations in adrenocorticotrophin (ACTH) and cortisol and the simultaneous increase of $\mathrm{CRH}, \mathrm{ACTH}$, and cortisol in the maternal and fetal compartments over the course of gestation (67). Because in the nonpregnant state, stress and mood disorders can be associated with increased activation of the HPA system. It is estimated that $\sim 10-20 \%$ of maternal cortisol passes through to the fetus (67-69). Maternal cortisol levels are positively correlated with fetal plasma cortisol levels $(68,70)$. Glucocorticoid exposure can affect synaptogenesis, neurotransmitter 
function, and glucocorticoid receptor expression in the developing brain (11) and thus also can impact the development of the HPA axis and the autonomic nervous system (ANS). Sandman et al. (71), found that higher levels of placentaderived $\mathrm{CRH}$ (pCRH) is linked to increased fetal HR reactivity (arousal) studied in a vibroaccoustic habituation paradigm. By using a laboratory stressor paradigm, Fink et al. found that fetuses of women who had a cortisol increase after an arithmetic task, versus those who did not, had higher resting HR and less short-term HR variability $20 \mathrm{~min}$ after the stressor task ended. There was a trend finding for participants who had a cortisol increase to report higher levels of life stress (72). In other work, higher resting maternal cortisol during the third trimester of pregnancy was associated with greater amplitude and amount (time spent) of fetal movement during a 50-min observation period (73). Elevated maternal cortisol and $\mathrm{CRH}$ levels during pregnancy have also been associated with increased infant negativity and fussiness $(29,74)$. Fetal exposure to synthetic glucocorticoids (betamethasone) for anticipated preterm birth predicts blunted infant cortisol reactivity and increased HR reactivity at 7 mo (75). However, other studies indicate that pregnant women's cortisol is only modestly associated with distress $(76,77)$ and variation in fetal and infant neurobehavior $(39,77)$, and that cortisol and maternal distress may have independent effects on infant outcomes (76-78).

Prenatal SSRI exposure also may impact the fetus via neuroendocrine processes. Ovine studies indicate that i.v. fluoxetine treatments in pregnant ewes increases ACTH and cortisol levels in the fetus (79). Changes in cortisol levels indicate that fluoxetine exposure may affect the developing HPA axis, which may affect postnatal and early neurodevelopment, although this study did not follow the animals past the early postnatal stage (79).

Placenta. In humans, the placental enzyme $11 \beta$-HSD-2 forms a barrier to maternal glucocorticoids, although under conditions of increased prenatal stress, there is increased maternal glucocorticoid production and reduced $11 \beta$-HSD-2 production (80), exposing the fetus to higher levels of glucocorticoids. In a recent study, maternal plasma and amniotic fluid cortisol were correlated after 18 wk gestation, and women's anxiety moderated the association such that there was a strong positive relationship $(r=0.59)$ for highly anxious women, and a nonsignificant correlation in the least anxious group (64). These findings suggest that antenatal anxiety in particular may affect placental function, which in turn, regulates fetal exposure to maternal cortisol and impacts fetal development.

Vascular functioning. Another potential pathway by which maternal psychiatric symptoms may contribute to vulnerability in the offspring is variation in uterine or umbilical blood flow (UBF). Importantly, SSRIs also have vasoconstrictive effects.

Studies are inconsistent with respect to associations between maternal prenatal distress and variation in UBF. Two early reports in the third trimester described positive associations between high self-reported anxiety and indices of resistance in the umbilical artery (81) and in the uterine arteries
(82). However, in a study conducted at 20 wk gestationpurportedly the optimal time for testing resistance (83), there were no associations between anxiety and uterine artery resistance (84). In a single study of UBF in women with psychiatric illness, having a disorder and/or current psychological distress did not associate with "abnormal" blood flow (85). The dichotomized characterization of UBF as clinically "normal" or "abnormal" does not adequately address the question of variability in flow related to psychiatric status. Finally, two recent studies were largely unsupportive of any association between women's distress and indices of restricted blood flow in the second or third trimester once confounds such as BMI and parity were included (86), except for those in the third trimester reporting distress levels at the cut off for reaching criteria for a psychiatric disorder (87).

Significant methodological variability across these studies (i.e. gestational timing of Doppler assessment, method of symptom assessment, timing of symptom assessment relative to blood flow evaluation, and indices used for characterizing blood flow) makes it difficult to draw conclusions as to whether UBF is a mediator of the association between prenatal psychiatric symptoms and at-risk neurobehavioral development.

Serotonin is a uterine vasoconstrictor, which can impact fetal development; in animal studies, fluoxetine administration is associated with a transient decrease in uterine blood flow (88), and direct injection of serotonin into the uterine vasculature was found to acutely reduce blood flow by $20 \%$ (88).

Finally, animal models of prenatal SSRI exposure have revealed specific pathways by which use of this medication may impact neurobehavioral development. Serotonin functions as a trophic factor and neurotransmitter during development, affecting critical developmental processes such as cell migration, neuronal division, and synaptogenesis; if serotonin levels are atypical (either too high or too low), these development processes are altered $(89,90)$. Although serotonin transporter expression in the adult brain is limited to the neurons of the raphe nucleus, the work of Gaspar and coworkers has demonstrated that during fetal development, it is also transiently expressed in other brain regions, including corticolimbic pathways in rodents and sensory afferents in some nonhuman primates. Prenatal SSRI exposure may alter developmental pathways in nonserotonergic neurons, with effects dependent on the timing of exposure and the transient fetal serotonin transporter expression in these regions (91).

\section{Conclusion}

By the time a child first enters a pediatrician's office, the complex interplay of genes and experience (8) has already contributed to his or her developmental processes as being more or less adaptive and more or less on the path to neuropsychiatric disorder-which is not to dismiss the tremendous plasticity and potential to respond to a range of interventions. This review summarized research extending the window of this complex interplay before birth such that prenatal exposure to maternal psychiatric illness and its treatment is included as 
an environmental factor, and a "third path" by which familial transmission of risk for neuropsychiatric disorders may occur.

\section{REFERENCES}

1. Kessler RC, Berglund P, Demler O, Jin R, Merikangas KR, Walters EE 2005 Lifetime prevalence and age-of-onset distributions of DSM-IV disorders in the National Comorbidity Survey Replication. Arch Gen Psychiatry 62:593-602

2. Kessler RC, Berglund P, Demler O, Jin R, Koretz D, Merikangas KR, Rush AJ, Walters EE, Wang PS 2003 The epidemiology of major depressive disorder: results from the National Comorbidity Survey Replication (NCS-R). JAMA 289:3095-3105

3. Marcus SM 2009 Depression during pregnancy: rates, risks and consequencesmotherisk update 2008. Can J Clin Pharmacol 16:e15-e22

4. Heron J, O'Connor TG, Evans J, Golding J, Glover V 2004 The course of anxiety and depression through pregnancy and the postpartum in a community sample. J Affect Disord 80:65-73

5. Bakker MK, Kolling P, van den Berg PB, de Walle HE, de Jong van den Berg LT 2008 Increase in use of selective serotonin reuptake inhibitors in pregnancy during the last decade, a population-based cohort study from the Netherlands. Br J Clin Pharmacol 65:600-606

6. Alwan S, Reefhuis J, Rasmussen SA, Friedman JM 2010 National Birth Defects Prevention Study Patterns of antidepressant medication use among pregnant women in a United States population. J Clin Pharmacol 51:264-270

7. Cooper WO, Willy ME, Pont SJ, Ray WA 2007 Increasing use of antidepressants in pregnancy. Am J Obstet Gynecol 196:544.e1-544.e5

8. Bale TL, Baram TZ, Brown AS, Goldstein JM, Insel TR, McCarthy MM, Nemeroff CB, Reyes TM, Simerly RB, Susser ES, Nestler EJ 2010 Early life programming and neurodevelopmental disorders. Biol Psychiatry 68:314-319

9. Fonagy P, Target M 1997 Attachment and relective function: their role in selforganiztion. Dev Psychopathol 9:679-700

0. Weissman MM, Warner V, Wickramaratne P, Moreau D, Olfson M 1997 Offspring of depressed parents. Arch Gen Psychiatry 54:932-940

11. Owen D, Andrews MH, Matthews SG 2005 Maternal adversity, glucocorticoids and programming of neuroendocrine function and behaviour. Neurosci Biobehav Rev 29:209-226

12. Talge NM, Neal C, Glover V 2007 Antenatal maternal stress and long-term effects on child neurodevelopment: how and why? J Child Psychol Psychiatry 48:245-261

13. DiPietro JA, Novak MF, Costigan KA, Atella LD, Reusing SP 2006 Maternal psychological distress during pregnancy in relation to child development at age two. Child Dev 77:573-587

14. O'Connor TG, Heron J, Golding J, Beveridge M, Glover V 2002 Maternal antenatal anxiety and children's behavioral/emotional problems at 4 years: report from the Avon Longitudinal Study of Parents and Children. Br J Psychiatry 180:502-508

15. Pawlby S, Hay DF, Sharp D, Waters CS, O'Keane V 2009 Antenatal depression predicts depression in adolescent offspring: prospective longitudinal communitybased study. J Affect Disord 113:236-243

16. O'Connor TG, Heron J, Glover V 2002 The ALSPAC Study Team Antenatal anxiety predicts child behavior/emotional problems independently of postnatal depression. J Am Acad Child Adolesc Psychiatry 41:1470-1477

17. O'Connor TG, Heron J, Golding J, Glover V 2003 Maternal antenatal anxiety and behavioural/emotional problems in children: a test of a programming hypothesis. J Child Psychol Psychiatry 44:1025-1036

18. O'Connor TG, Ben-Shlomo Y, Heron J, Golding J, Adams D, Glover V 2005 Prenatal anxiety predicts individual differences in cortisol in pre-adolescent children. Biol Psychiatry 58:211-217

19. Van den Bergh BR, Marcoen A 2004 High antenatal maternal anxiety is related to ADHD symptoms, externalizing problems and anxiety in 8-9 year olds. Child Dev 75:1085-1097

20. Van den Bergh BR, Mennes M, Oosterlaan J, Stevens V, Stiers P, Marcoen A, Lagae L 2005 High antenatal maternal anxiety is related to impulsivity during performance on cognitive tasks in 14- and 15-year-olds. Neurosci Biobehav Rev 29:259-269

21. van den Bergh BR, Mennes M, Stevens V, van der Meere J, Borger N, Stiers P, Marcoen A, Lagae L 2006 ADHD deficit as measured in adolescent boys with a continuous performance task is related to antenatal maternal anxiety. Pediatr Res $59 \cdot 78-82$

22. Van den Bergh BR, Van Calster B, Smits T, Van Huffel S, Lagae L 2008 Antenata maternal anxiety is related to HPA-axis dysregulation and self-reported depressive symptoms in adolescence: a prospective study on the fetal origins of depressed mood. Neuropsychopharmacology 33:536-545

23. Buss C, Davis EP, Muftuler LT, Head K, Sandman CA 2010 High pregnancy anxiety during mid-gestation is associated with decreased gray matter density in 6-9-yearold children. Psychoneuroendocrinology 35:141-153

24. Pruessner JC, Dedovic K, Khalili-Mahani N, Engert V, Pruessner M, Buss C, Renwick R, Dagher A, Meaney MJ, Lupien S 2008 Deactivation of the limbic system during acute psychosocial stress: evidence from positron emission tomography and functional magnetic resonance imaging studies. Biol Psychiatry 63:234-240

25. Evans GW, Gonnella C, Marcynyszyn LA, Gentile L, Salpekar N 2005 The role of chaos in poverty and children's socioemotional adjustment. Psychol Sci 16:560-565

26. Abrams SM, Field T, Scafidi F, Prodromidis M 1995 Newborns of depressed mothers. Infant Ment Health J 16:233-239

27. Field T, Diego M, Dieter J, Hernandez-Reif M, Schanberg S, Kuhn C, Yando R, Bendell D 2004 Prenatal depression effects on the fetus and the newborn. Infant Behav Dev 27:216-229

28. Brouwers AP, van Baar AL, Pop VJ 2001 Maternal anxiety during pregnancy and subsequent infant development. Infant Behav Dev 24:95-106
29. Davis PE, Snidman N, Wadhwa P, Glynn LM, Schetter CD, Sandman CA 2004 Prenatal maternal anxiety and depression predict negative behavioral reactivity in infancy. Infancy 6:319-331

30. Werner EA, Myers MM, Fifer WP, Cheng B, Fang Y, Allen R, Monk C 2007 Prenatal predictors of infant temperament. Dev Psychobiol 49:474-484

31. Brennan PA, Le Brocque R, Hammen C 2003 Maternal depression, parent-child relationships, and resilient outcomes in adolescence. J Am Acad Child Adolesc Psychiatry 42:1469-1477

32. Brand SR, Engel SM, Canfield RL, Yehuda R 2006 The effect of maternal PTSD following in utero trauma exposure on behavior and temperament in the 9-month-old infant. Ann N Y Acad Sci 1071:454-458

33. Warren SL, Gunnar MR, Kagan J, Anders TF, Simmens SJ, Rones M, Wease S, Aron E, Dahl RE, Sroufe LA 2003 Maternal panic disorder: infant temperament, neurophysiology, and parenting behaviors. J Am Acad Child Adolesc Psychiatry 42:814-825

34. Kaplan LA, Evans L, Monk C 2008 Effects of mothers' prenatal psychiatric status and postnatal caregiving on infant biobehavioral regulation: can prenatal programming be modified? Early Hum Dev 84:249-256

35. Grant KA, McMahon C, Austin MP, Reilly N, Leader L, Ali S 2009 Maternal prenatal anxiety, postnatal caregiving and infants' cortisol responses to the still-face procedure. Dev Psychobiol 51:625-637

36. Field T, Diego M, Hernandez-Reif M, Vera Y, Gil K, Schanberg S, Kuhn C, Gonzalez-Garcia A 2004 Prenatal maternal biochemistry predicts neonatal biochemistry. Int J Neurosci 114:933-945

37. McEwen BS, Gianaros PJ 2010 Central role of the brain in stress and adaptation: links to socioeconomic status, health, and disease. Ann N Y Acad Sci 1186:190-222

38. Monk C, Myers MM, Sloan RP, Werner L, Jeon J, Tager F, Fifer WP 2004 Fetal heart rate reactivity differs by women's psychiatric status: an early marker for developmental risk? J Am Acad Child Adolesc Psychiatry 43:283-290

39. Monk C, Fifer WP, Myers MM, Bagiella E, Duong JK, Chen IS, Leotti L, Altincatal A 2010 Effects of maternal breathing rate, psychiatric status, and cortisol on fetal heart rate. Dev Psychobiol, [epub ahead of print]

40. Allister L, Lester BM, Carr S, Liu E 2001 The effects of maternal depression on fetal heart rate responce to vibroacoustic stimulation. Dev Neuropsychol 20:639-651

41. DiPietro JA, Caulfield L, Costigan KA, Merialdi M, Nguyen RH, Zavaleta N, Gurewitsch ED 2004 Fetal neurobehavioral development: a tale of two cities. Dev Psychol 40:445-456

42. Dieter J, Emory E, Johnson K, Raynor B 2008 Maternal depression and anxiety effects on the human fetus: preliminary findings and clinical implications. Infant Ment Health J 29:420-441

43. DiPietro JA, Ghera MM, Costigan KA 2008 Prenatal origins of temperamental reactivity in early infancy. Early Hum Dev 84:569-575

44. Weinstock M 2005 The potential influence of maternal stress hormones on development and mental health of the offspring. Brain Behav Immun 19:296-308

45. Rice F, Harold GT, Boivin J, van den Bree M, Hay DF, Thapar A 2010 The links between prenatal stress and offspring development and psychopathology: disentangling environmental and inherited influences. Psychol Med 40:335-345

46. Golombok S, Lycett E, MacCallum F, Jadva V, Murray C, Rust J, Abdalla H, Jenkins J, Margara R 2004 Parenting infants conceived by gamete donation. J Fam Psychol 18:443-452

47. Moses-Kolko EL, Bogen D, Perel J, Bregar A, Uhl K, Levin B, Wisner KL 2005 Neonatal signs after late in utero exposure to serotonin reuptake inhibitors: literature review and implications for clinical applications. JAMA 293:2372-2383

48. Galbally M, Lewis AJ, Lum J, Buist A 2009 Serotonin discontinuation syndrome following in utero exposure to antidepressant medication: prospective controlled study. Aust N Z J Psychiatry 43:846-854

49. Ferreira E, Carceller AM, Agogué C, Martin BZ, St-André M, Francoeur D, Bérard A 2007 Effects of selective serotonin reuptake inhibitors and venlafaxine during pregnancy in term and preterm neonates. Pediatrics 119:52-59

50. Levinson-Castiel R, Merlob P, Linder N, Sirota L, Klinger G 2006 Neonata abstinence syndrome after in utero exposure to selective serotonin reuptake inhibitors in term infants. Arch Pediatr Adolesc Med 160:173-176

51. Warburton W, Hertzman C, Oberlander TF 2010 A register study of the impact of stopping third trimester selective serotonin reuptake inhibitor exposure on neonatal health. Acta Psychiatr Scand 121:471-479

52. Zeskind PS, Stephens LE 2004 Maternal selective serotonin reuptake inhibitor use during pregnancy and newborn neurobehavior. Pediatrics 113:368-375

53. Oberlander TF, Grunau RE, Fitzgerald C, Papsdorf M, Rurak D, Riggs W 2005 Pain reactivity in 2-month-old infants after prenatal and postnatal serotonin reuptake inhibitor medication exposure. Pediatrics 115:411-425

54. Oberlander TF, Grunau R, Mayes L, Riggs W, Rurak D, Papsdorf M, Misri S, Weinberg J 2008 Hypothalamic-pituitary-adrenal (HPA) axis function in 3-month old infants with prenatal selective serotonin reuptake inhibitor (SSRI) antidepressant exposure. Early Hum Dev 84:689-697

55. Nulman I, Rovet J, Stewart DE, Wolpin J, Pace-Asciak P, Shuhaiber S, Koren G 2002 Child development following exposure to tricyclic antidepressants or fluoxetine throughout fetal life: a prospective, controlled study. Am J Psychiatry 159:1889-1895

56. Casper RC, Fleisher BE, Lee-Ancajas JC, Gilles A, Gaylor E, DeBattista A, Hoyme HE 2003 Follow-up of children of depressed mothers exposed or not exposed to antidepressant drugs during pregnancy. J Pediatr 142:402-408

57. Pedersen LH, Henricksen TB, Olsen J 2010 Fetal exposure to antidepressants and normal milestone development at 6 and 19 months of age. Pediatrics 125:e600-e608

58. Misri S, Reebye P, Kendrick K, Carter D, Ryan D, Grunau RE, Oberlander TF 2006 Internalizing behaviors in 4-year-old children exposed in utero to psychotropic medications. Am J Psychiatry 163:1026-1032 
59. Oberlander TF, Reebye P, Misri S, Papsdorf M, Kim J, Grunau RE 2007 Externalizing and attentional behaviors in children of depressed mothers treated with a selective serotonin reuptake inhibitor antidepressant during pregnancy. Arch Pediatr Adolesc Med 161:22-29

60. Oberlander TF, Papsdorf M, Brain UM, Misri S, Ross C, Gruneau RE 2010 Prenatal effects of selective serotonin reuptake inhibitor antidepressants, serotonin transporter promoter genotype (SLC6A4), and maternal mood on child behavior at 3 years of age. Arch Pediatr Adolesc Med 164:444-451

61. Ansorge MS, Morelli E, Gingrich JA 2008 Inhibition of serotonin but not norepinephrine transport during development produces delayed, persistent perturbations of emotional behaviors in mice. J Neurosci 28:199-207

62. Maciag D, Coppinger D, Paul IA 2006 Evidence that the deficit in sexual behavior in adult rats neonatally exposed to citalopram is a consequence of 5-HT1 receptor stimulation during development. Brain Res 1125:171-175

63. Wadhwa PD, Glynn L, Hobel CJ, Garite TJ, Porto M, Chicz-DeMet A, Wigelsworth AK, Sandman CA 2002 Behavioral perinatology: biobehavioral processes in human fetal development. Regul Pept 108:149-157

64. Sarkar P, Bergman K, O'Connor TG, Glover V 2008 Maternal antenatal anxiety and amniotic fluid cortisol and testosterone: possible implications for foetal programming. J Neuroendocrinol 20:489-496

65. Teixeira J, Martin D, Prendiville O, Glover V 2005 The effects of acute relaxation on indices of anxiety during pregnancy. J Psychosom Obstet Gynaecol 26:271-276

66. Mairesse J, Lesage J, Breton C, Breant B, Hahn T, Darnaudery M, Dickson SL, Seckl J, Blondeau B, Vieau D, Maccari S, Viltart O 2007 Maternal stress alters endocrine function of the feto-placental unit in rats. Am J Physiol Endocrinol Metab 292:E1526-E1533

67. Petraglia F, Florio P, Nappi C, Genazzani AR 1996 Peptide signaling in human placenta and membranes: autocrine, paracrine, and endocrine mechanisms. Endocr Rev 17:156-186

68. Gitau R, Cameron A, Fisk NM, Glover V 1998 Fetal exposure to maternal cortisol Lancet 352:707-708

69. Sarkar P, Bergman K, Fisk NM, O'Connor TG, Glover V 2007 Ontogeny of foeta exposure to maternal cortisol using midtrimester amniotic fluid as a biomarker. Clin Endocrinol (Oxf) 66:636-640

70. Gitau R 2001 Umbilical cord cortisol levels as an incidacator of the fetal stress response to assisted vaginal delivery. Eur J Obstet Gynecol Reprod Biol 98:14-17

71. Sandman CA, Wadhwa P, Glynn L, Chicz-Demet A, Porto M, Garite TJ 1999 Corticotrophin-releasing hormone and fetal responses in human pregnancy. Ann N Y Acad Sci 897:66-75

72. Fink NS, Urech C, Berger CT, Hoesli I, Holzgreve W, Bitzer J, Alder J 2010 Maternal laboratory stress influences fetal neurobehavior: cortisol does not provide all answers. J Matern Fetal Neonatal Med 23:488-500

73. DiPietro JA, Kivlighan KT, Costigan KA, Laudenslager ML 2009 Fetal motor activity and maternal cortisol. Dev Psychobiol 51:505-512

74. de Weerth C, van Hees Y, Buitelaar JK 2003 Prenatal maternal cortisol levels and infant behavior during the first 5 months. Early Hum Dev 74:139-151
75. Davis EP, Townsend EL, Gunnar MR, Guiang SF, Lussky RC, Cifuentes RF, Georgieff MK 2006 Antenatal betamethasone treatment has a persisting influence on infant HPA axis regulation. J Perinatol 26:147-153

76. Davis EP, Sandman CA 2010 The timing of prenatal exposure to maternal cortisol and psychosocial stress is associated with human infant cognitive development. Child Dev 81:131-148

77. Davis EP, Glynn LM, Schetter CD, Hobel C, Chicz-Demet A, Sandman CA 2007 Prenatal exposure to maternal depression and cortisol influences infant temperament. J Am Acad Child Adolesc Psychiatry 46:737-746

78. Bergman K, Glover V, Sarkar P, Abbott DH, O'Connor TG 2010 In utero cortisol and testosterone exposure and fear reactivity in infancy. Horm Behav 57:306-312

79. Morrison JL, Riggs KW, Chien C, Gruber N, McMillen IC, Rurak DW 2004 Chronic maternal fluoxetine infusion in pregnant sheep: effects on the maternal and fetal hypothalamic-pituitary-adrenal axes. Pediatr Res 56:40-46

80. Cottrell EC, Seckl JR 2009 Prenatal stress, glucocorticoids and the programming of adult disease. Front Behav Neurosci 3:19

81. Sjöström K, Valentin L, Thelin T, Marsal K 1997 Maternal anxiety in late pregnancy and fetal hemodynamics. Eur J Obstet Gynecol Reprod Biol 74:149-155

82. Teixeira JM, Fisk NM, Glover V 1999 Association between maternal anxiety in pregnancy and increased uterine artery resistance index: cohort based study. BMJ 318:153-157

83. Sciscione AC, Hayes EJ 2009 Uterine artery Doppler flow studies in obstetric practice. Am J Obstet Gynecol 201:121-126

84. Kent A, Hughes P, Ormerod L, Jones G, Thilaganathan B 2002 Uterine artery resistance and anxiety in the second trimester of pregnancy. Ultrasound Obstet Gynecol 19:177-179

85. Maina G, Saracco P, Giolito MR, Danelon D, Bogetto F, Todros T 2008 Impact of maternal psychological distress on fetal weight, prematurity and intrauterine growth retardation. J Affect Disord 111:214-220

86. Harville EW, Savitz DA, Dole N, Herring AH, Thorp JM, Light KC 2008 Stress and placental resistance measured by Doppler ultrasound in early and mid-pregnancy. Ultrasound Obstet Gynecol 32:23-30

87. Vythilingum B, Geerts L, Fincham D, Roos A, Faure S, Jonkers J, Stein DJ 2010 Association between antenatal distress and uterine artery pulsatility index. Arch Womens Ment Health 13:359-364

88. Morrison JL, Chien C, Riggs KW, Gruber N, Rurak D 2002 Effect of maternal fluoxetine administration on uterine blood flow, fetal blood gas status, and growth. Pediatr Res 51:433-442

89. Ansorge MS, Hen R, Gingrich JA 2007 Neurodevelopmental origins of depressive disorders. Curr Opin Pharmacol 7:8-17

90. Ansorge MS, Zhou M, Lira A, Hen R, Gingrich JA 2004 Early-life blockade of the 5-HT transporter alters emotional behavior in adult mice. Science 306:879-881

91. Homberg JR, Schubert D, Gaspar P 2010 New perspectives on the neurodevelopmental effects of SSRIs. Trends Pharmacol Sci 31:60-65 